\title{
TITLE: How do neighboring peer companies influence SMEs' financial behavior?
}

Authors: Mariluz Maté-Sánchez-Val*, Fernando López-Hernandez**; Jesús MurLacambra***

(*) Department of Financial Economics and Accounting at the Technical University of Cartagena. Post-mail: Calle Real 3, 30201, Cartagena (Murcia) Spain. Corresponding author.

(**) Department of Quatitative Methods and Computing at the Technical University of Cartagena. Post mail: Calle Real 3, 30201, Cartagena (Murcia) Spain.

$\left.{ }^{(* * *}\right)$ Department of Economic Analysis. Post mail: Faculty of Economics María de Luna, s/n, Campus ‘Rio Ebro’ University of Zaragoza. 50018 Zaragoza Spain.

Acknowledgments We gratefully acknowledge the contribution of three anonymous reviewers in helping us improve the quality of this paper. Prof. Fernando A. López and Mariluz Maté thanks the financial support offered by the project from Programa de Ayudas a Grupos de Excelencia de la Región de Murcia, Fundación Séneca (\#19884GERM-15). Jesús Mur and Fernando López acknowledge financial support from the Ministerio de Economía y Competitividad under grant ECO2015-651758-P. Jesus Mur thanks the financial help provided by the Gobierno de Aragón, in collaboration with FEDER. 


\section{Highlights}

- The relevance of geographically neighboring companies on the financial decisions taken by a company is examined.

- We find nonlinearities in the adjustment process of financial ratios when some basic characteristics of the company are considered.

- We conclude that reactive environments favor the responsiveness of companies under changes in local environments. 


\section{Introduction}

Recent research into corporate finances has found that the financial decisions of peer companies tend to be related. Companies tend to "kept an eye" on the decisions of other companies, which can be attributed to problems caused by the lack of information (Granovetter, 1985). Managers work under conditions of high uncertainty, with partial and asymmetric information that limits their capacity to make optimal decisions; thus, decisions taken by other companies are of great importance for them (Leary and Robert, 2014). However, peer effects on firms' financial decisions have been scarcely considered. From an empirical perspective, Graham and Harvey (2011), based on a questionnaire intended for a significant number of chief financial officers (CFOs), place a high value on the financial decisions of other peer companies when devising companies' strategies. Leary and Roberts (2014) analyze this effect giving direct evidence of peer effects in firm financial decisions.

In fact, these results can be connected to Manski (1993) model. Interaction between companies is produced through a social network, a structure made of nodes, companies, which are tied by dependence relations in their financial decisions. There is interaction because the behaviour of a company adapts to the collective behaviour of its reference group (its neighbours), that is the peer effect, and also because the exogenous factors associated to this group may have an impact on the decisions of the company; that is the contextual effect. We may also think in the so-called correlated effect arising from the unobservables that, for example, may encourage some companies to locate near other companies to benefit from different types of agglomeration economies; this case of endogenous location will not be considered here. Assuming that the location is exogenous, there may be unobservables reflecting environmental or institutional influences that have an impact on the decisions of the companies located in the area.

The ability of a company to obtain information from its peers may be affected by its size. Leary and Robert (2014) analyse this effect obtaining that small companies are more sensible to peer effects. It is clear that small and medium enterprises (SMEs) are at a disadvantage compared to large companies. Managers in small companies must cope with severe restrictions on information because they do not have easy access to experts and specialized information channels (Carreira and Silva, 2010). Information is critical to making good decisions, and therefore SME managers often attempt to compensate this deficit by using information from different sources (for example, local or regional surroundings, informal channels in the industry, etc.). In addition, small companies have 
stronger incentives to correct for unbalances because their high (relative) costs resulting from them (Davis and Peles, 1993). Therefore, SMEs are more prone to mimicking financial practices because they seek to improve their performance. This is not the case for large companies, which have enough resources to monitor the markets and competitors by themselves (Reppenhagen, 2010).

Recent literature has brought up another issue: geography. According to Carbó et al., (2003) and Degryse and Ongena (2005), asymmetric information problems and agency costs are reduced by proximity. Indeed, there are numerous studies that evaluate the impact of the distance between firms and its capital providers such as investors (Brown et al., 2014; O’Brien and Tan, 2015) or financial entities (Knyazeva and Knyazeva, 2012; Rao et al., 2015). However, the effects of proximity to other peer companies on a firm's financial decisions have been less treated. Degryse and Ongena (2005) maintain that clustering and geographical proximity favor the flow of information between companies. Fernández and Maudos (2009) and Palacín-Sánchez and Di Pietro (2015) point out the role of banks in sharing common practices. It should be noted here that bank branches focus on segmented local markets, the same as other financial agents (Massa and Simonov, 2006; Uysal et al., 2008).

Treacy and Carey (2000) point to the use of credit score models specific to each bank. The score models provide different assessments for different companies and follow a certain geographical pattern that discriminates between locations. Conversely, this procedure offers implicit information to the companies in the area on which "good" standards are preferred by the financial system. Another example of informal geographical segmentation is suppliers providing selling prices and financing conditions according to the situation of each local market. The result is a kind of soft geographical segmentation of the financial markets, where slight but relevant different conditions apply to the various areas. Companies located in the same local market will face similar financial conditions, which are different from other areas, favoring the appearance of a similar financial structure.

Another strand of literature has concluded that the existence of non-economic, informal factors is related to geographical proximity. Pirinsky and Wang (2010) have noted a "co-movement in the stock returns of firms headquartered in the same area"; this co-movement is attributed to a regional, unobservable pattern that can be proxied by a set of local indicators. Gao et al. (2013), more explicitly, maintain that the location of firms partly explains their capital structures and payout policies; in fact, they 
demonstrate that companies located in the same area exhibit similar leverage and liquidity ratios. This similarity is not a coincidence, but is rather the result of unobserved local effects and the interaction between companies.

Managers working in the same area normally have opportunities to build face-toface relationships, exchange ideas and learn from others' experiences. Local environments facilitate such interactions. Davis and Greve (1997) mention social and professional clubs which can promote informal activities. Mizruchi (1996) points to the practice of sharing staff members on respective boards of directors (a board interlock). In such cases, firms will have direct access to the decision-making process of other companies through board interlock.

Anyway, it is clear that proximity improves the transmission channels strengthening peer effects in financial decisions among companies, and this is our main hypothesis here.

The purpose of our research is twofold. First, we test for the existence of interaction effects in the financial decisions made by a representative group of Spanish industrial companies. Moreover, as previously stated, our hypothesis is that geographical proximity promotes convergence among peers. Second, we aim to prove that the peer effects, arising from geographical proximity, fit to the characteristics of the companies. As indicated, small companies have greater incentives to adjust their financial ratios than large corporations, the same applies to high and low tech companies, old vs young companies or firms working in national or international markets. Thus, we expect to find significant nonlinearities in the data. In this context, we examine the financial behavior of a large group of Spanish companies using a Partial Adjustment Model (PAM). Our analysis is supported by three financial ratios representative of each firm' financial dimension: liquidity, indebtedness and profitability (Soboh et al., 2009).

The structure of the paper is as follows: Section 2 introduces the well-known PAM model, including spatial interaction effects. Section 3 discusses the data that support our study. Section 4 estimates de different equations implied by the interaction hypothesis and Section 5 concludes with a summary of main results.

\section{A nonlinear partial adjustment model}

To test the interaction hypothesis between neighboring peer companies we use a classic PAM, which has been modified by the inclusion of spatial effects. As is well 
known, PAM models assume that the financial ratios of the firms evolve over time owing to adjustment towards optimal values (Lev, 1969). Given an external shock that disturbs previous equilibriums, companies should reconsider their financial objectives. The problem is the lack of suitable information for the companies to set the new optimum, which leads to them using reference values such as industrial averages.

Companies with financial ratios far from their benchmarks incur costs by being out of equilibrium, which are usually higher than the adjustment costs. Thus, managers change accounting practices (e.g., they use inventory evaluation methods, substituting short-term for long-term debt, etc.) to readjust their financial ratios. In addition, market forces press the financial magnitudes of the whole industry in the same way. For example, the expectation of high returns will attract new companies to enter the industry, driving profitability ratios toward sustainable values (Peles and Schneller, 1988).

\subsection{The classical PAM}

The PAM model was originally proposed by Lev (1969) and has become a very popular technique in applied research. The model is very simple. Its main assumption states that changes in an indicator under the control of company i in period $t, Y_{i t}$, adjusts proportionally to the gap between the optimal amount in period t, $\mathrm{Y}_{\text {it }}^{*}$ and the observed amount in (t-1), $\mathrm{Y}_{\mathrm{it}-1}$. The adjustment resulting from different causes such as markets rigidities, fixed costs or indivisibilities may be instantaneous or not. In brief:

$$
\mathrm{Y}_{\mathrm{it}}-\mathrm{Y}_{\mathrm{it}-1}=\delta\left(\mathrm{Y}_{\mathrm{it}}^{*}-\mathrm{Y}_{\mathrm{it}-1}\right)+\mathrm{e}_{\mathrm{it}}
$$

where $\delta$ is a parameter that measures the speed of adjustment and $\mathrm{e}_{\mathrm{it}}$ is an error term. According to (1), the speed of adjustment $\delta$ is the ratio between the optimal change, $\left(Y_{i t}^{*}-Y_{i t-1}\right)$ and the observed change $Y_{i t}-Y_{i t-1}$. To conclude in favor of the existence of an adjustment process, $\delta$ should remain between 0 and 1 . In the case of $\delta=0$, there is no adjustment and the indicator maintains the same value. At the other extreme, if $\delta=1$ the gap is corrected instantaneously, $\mathrm{Y}_{\mathrm{it}}^{*}=\mathrm{Y}_{\mathrm{it}}$. According to the applied literature, $\delta$ is usually an interior point of the interval $(0,1)$, where the adjustment is incomplete or is only partially complete; hence the name Partial Adjustment Model. 
Let us note that the objective, $\mathrm{Y}_{\mathrm{it}}^{*}$, is not observable and must be estimated in advance in order to build a PAM model. Several proposals have been made in the literature, e.g., by Lev (1969, note 2), who suggests estimating this optimal value by using the industrial average in period $(\mathrm{t}-1)$.

\subsection{A nonlinear PAM model}

There is a large literature devoted to PAM models that has put forward criticisms and suggestions (e.g., Gallizo et al., 2008 or Mate et al., 2012). In our case, we are going to focus on the assumption of a homogeneous speed of adjustment. This is a sensible hypothesis only for a uniform set of companies; however, when using a heterogeneous group, as is usually the case, the hypothesis should be relaxed. Lev (1969) highlights the relevance of the problem: 'In (...) a large and heterogeneous sample, there is no way to identify specific techniques which probably differ from firm to firm' (p. 299). Taking into account this limitation, several authors have dealt with the "heterogeneity question" by examining the link between financial ratio adjustment processes and companies' characteristics (Lee and Wu, 1988; Seay et al., 2004, AybarArias et al., 2012).

Faulkender et al. (2012) find strong nonlinearities in their study on the dynamics of corporate financial ratios, which they attribute to firms' characteristics. Their conclusion is that this effect 'should be incorporated in empirical studies of corporate leverage' to reduce estimation biases and inconsistencies. We follow their suggestion by introducing a simple set of dummy variables in the PAM equation of (1):

$$
\mathrm{Y}_{\mathrm{it}}-\mathrm{Y}_{\mathrm{it}-1}=\delta\left(\mathrm{Y}_{\mathrm{it}}^{*}-\mathrm{Y}_{\mathrm{it}-1}\right)+\sum_{\mathrm{k}=1}^{\mathrm{K}-1} \delta_{\mathrm{k}}\left(\mathrm{Y}_{\mathrm{it}}^{*}-\mathrm{Y}_{\mathrm{it}-1}\right) \mathrm{g}_{\mathrm{k}}+\mathrm{e}_{\mathrm{it}}
$$

where $\mathrm{g}_{\mathrm{k}},\{\mathrm{k}=1, \ldots, \mathrm{K}-1\}$ is a binary variable which takes the value 1 if company $\mathrm{i}$ belongs to the category $\mathrm{k}$. As usual, $\delta$ is the coefficient that measures adjustment speed for the reference group (in this case, group $\mathrm{K}$ ), and $\delta_{\mathrm{k}}$ the speed differential corresponding to group $\mathrm{k}$ with respect to the K-th.

\subsection{Factors that impact on the speed of convergence}

The size and the economic activity of the firm are considered potential sources of heterogeneity in (1), but are not the only sources, as discussed below. 


\subsubsection{Distance to the optimum}

An element that often emerges as a relevant conditioning factor in the adjustment of financial ratios is the distance to the objective, which measures the disequilibrium that the company suffers at that moment. We expect that companies in worse situation, in the sense of being farthest from their optimum, assume greater efforts to reach their objectives since stronger disequilibrium means higher costs. On the contrary, companies whose financial ratios are closer to their objectives are less forced to take action and may tend to maintain their position. This reasoning also leads to a nonlinear structure of the PAM, allowing for different speeds of adjustment depending on the distance to the optimum, as suggested previously, for example, by Aybar-Arias et al. (2012) or Lee and Wu (1988).

\subsubsection{Size of firms}

Firm size is a very important factor in this discussion. Applied literature usually distinguishes between small and large companies. Lee and $\mathrm{Wu}$ (1988), analyze six financial ratios using a sample of large and small companies. They noted a positive and significant relationship between the size of the company and adjustment coefficients. Aybar-Arias et al. (2012) focus on the indebtedness ratio, arguing that large companies have, proportionally, smaller restructuration costs and, therefore, should have a higher speed of adjustment. However, we also find empirical studies with the opposite result. From this perspective, small companies have stronger incentives to correct the disequilibrium because (relatively) high costs of this situation (Davis and Peles, 1993). This is not, necessarily, the case for large companies which have easier access to information, technology and financial markets. In addition, their reduced dimension allows small firms quicker reactions having more flexibility and less bureaucracy than large firms. Wu and Ho (1997) demonstrate that smaller firms adjust ratios to the optimal value faster than large firms.

Under these circumstances, it is difficult to consider the existence of a general adjustment process common to all companies, which drives the financial ratios of the industry toward similar target values. On the contrary, we expect to find different adjustment processes for different groups of companies, depending on their size.

\subsubsection{Technological intensity}

Different industries mean different markets, each of which has different standards, institutions and competitive mechanisms. The hypothesis is that the 
company's proactivity in relation to changes in the environment, both general and immediate, depends on the characteristics of the market in which the company works. Lee and $\mathrm{Wu}$ (1988) detect strong differences in the adjustment processes that correspond to different industrial sectors, as do Chen and Ainina (1994), Gallizo and Salvador (2003) or Gallizo et al. (2008) using PAM models. This presumption extends to financial ratios.

\subsubsection{Regional characteristics}

Regional economics assesses positively the role of the so-called "institutional and financial" factors, which are defined as the combination of political, cultural and economic features that characterize each territory. As stated by Carbó et al. (2007), this mixture has a huge influence on firms' financial behavior in the territory, but there are few studies analyzing this impact in deep. Bonaccorsi and Gobbi (2001) find that the regional financial network, measured through the number of financial entities, greatly affects the quantity and quality of firms' credit. Similarly, Michelacci and Silva (2007) build a regional financial development indicator that determines firms' credit availability. Du and Xiu (2009) focus on the relationship between regional governments, regional markets and legal systems, highlighting the relevance of regional factors for the firms located in the territory. Fan et al. (2013) indicate that regions with dense and stronger social and economic networks also have robust economic systems that, among other things, provide adequate financing to their companies. In sum, according to the literature, it is important to control also for regional peculiarities in order to reduce heterogeneity in the adjustment processes.

\subsubsection{Import/Export Activities}

There is broad evidence that international corporate activity is one of the determinants of capital structure (Low and Chen, 2004 or Pacheco, 2016). Previous empirical studies conclude that multinational corporations tend to have lower leverage, financing their business with equity rather than debt due to risk considerations (e.g., exchange rate risk and/or political risk) (Desay et al., 2008). Pantzalis (2003) gives evidence about the higher agency costs for multinational companies in comparison with domestic firms. These higher costs will cause multinational companies have more incentives to adjust their financial ratios to the target values at quicker rates in order to avoid incur in additional risk costs. 


\subsubsection{Age}

Regarding previous studies, we find the age of a firm as an additional factor on its financial performance acting as an inverse proxy for volatility and for the costs of bankruptcy (Frank and Goyal, 2009; Cole, 2013). In this sense, older firms will have fewer incentives to adapt their financial structures to new, perhaps more adequate average values in comparison with newcomers. Thus, we should expect a lower adjustment rate for older companies.

\section{Interaction among companies. A heterogeneous PAM model with spatial effects.}

The interaction hypothesis implies not only that there is mutual dependence among peer companies, but also that interaction intensifies with geographical proximity. Following Leary and Robert's study (2015), we put forward three different channels to allow for the interaction between firms strengthened by proximity:

- An endogenous interaction effect, where the financial decisions of company i depend explicitly on the decisions taken by the companies located nearby. The literature on spatial econometrics uses the term Spatial Lag Model (SLM) to indicate that a "weighted" average of the reactions of the neighbors of company $i$ should appear in the right hand side of equation (2). This can be associated with the peer effect of Manski (1993).

- An exogenous interaction effect, where financial decisions of company i depends not only on the gap of company $\left.\mathrm{i}, \mathrm{Y}_{\mathrm{it}}^{*}-\mathrm{Y}_{\mathrm{it}-1}\right)$ but also on a "weighted" average of the gaps of the neighbors of company i. This situation receives the name Spatial Lag in X (SLX) variables in spatial econometrics literature, and corresponds to the contextual factors of Manski (1993).

- Finally, interaction may also appear from unobserved effects in the error terms of equation (1). This may be due to the omission of relevant variables in the equation, different from the gap in (1), to the existence of local features or regional trends (not modeled in the equation) or, simply, to weaker forms of cross-sectional interaction. This is a Spatial Error Model (SEM).

These models are commonly used in the field of spatial or regional economic analysis and are becoming popular in the more general setting of social interaction networks where the purpose is to calibrate the interrelationships between a set of networked individuals. It should be noted here that this is also our main objective. 
To further this objective, it is crucial to define the notion of closeness or "neighborhood," which is not evident. The literature on spatial econometrics suggests the use of the so-called 'contiguity or weighting matrix' denoted by $\mathrm{W}$. This is a matrix of order (nxn), where $\mathrm{n}$ is the number of individuals in the sample, specified exogenously, so that the researcher marks the units (companies) which are close to a given unit (company). For example, row i identifies the companies which are located in the neighborhood of company i whereas column i indicates to which companies the i-th firm is close to in the sample. The distinction between columns and rows should be read in terms of impacts (in the sense that column i identifies the companies that are influenced by company i, and row i the companies that affect company i). Obviously, this distinction is irrelevant in cases of purely symmetric relations, but symmetry is not always an acceptable restriction (consider the impact on the US economy of the Mexican economy and the impact on the Mexican economy from the US economy). The terms in the diagonal of $\mathbf{W}$ are set to zero, for identification purposes, and there is ample flexibility for defining the weights corresponding to the other terms, which are non-negative; $\omega_{\mathrm{ii}}=0$ for $\mathrm{i}=1, \ldots, \mathrm{n}$ and $\omega_{\mathrm{ij}} \geq 0 ; \mathrm{i} \neq \mathrm{j}$. We must recall that the specification of $\mathbf{W}$ is a very important decision because the weight matrix is supposed to reflect the structure of the connections that exist among the companies. In spite of that, the procedure of building $\mathbf{W}$ is rather informal. Corrado and Fingleton (2012) admit that there is not any protocol in the literature to guide the user on this point. Indeed, mainly ad hoc procedures dominate based on some measure of separation between the individuals (see Harris et al., 2011).

On these premises, we are going to consider three extensions to the basic interaction model of (2).

- The mixed partial adjustment model-spatial lag model, PAM-SLM:

$$
Y_{i t}-Y_{i t-1}=\delta\left(Y_{i t}^{*}-Y_{i t-1}\right)+\rho \sum_{j \neq i}^{n} \omega_{i j}\left(Y_{j t}-Y_{j t-1}\right)+\sum_{k=1}^{K-1} \delta_{k}\left(Y_{i t}^{*}-Y_{i t-1}\right) g_{k}+e_{i t}
$$

- The mixed partial adjustment model-spatial error model, PAM-SEM:

$$
\mathrm{Y}_{\mathrm{it}}-\mathrm{Y}_{\mathrm{it}-1}=\delta\left(\mathrm{Y}_{\mathrm{it}}^{*}-\mathrm{Y}_{\mathrm{it}-1}\right)+\sum_{\mathrm{k}=1}^{\mathrm{K}-1} \delta_{\mathrm{k}}\left(\mathrm{Y}_{\mathrm{it}}^{*}-\mathrm{Y}_{\mathrm{it}-1}\right) \mathrm{g}_{\mathrm{k}}+\mathrm{u}_{\mathrm{it}} ; \mathrm{u}_{\mathrm{it}}=\lambda \sum_{\mathrm{j} \neq \mathrm{i}}^{\mathrm{n}} \omega_{\mathrm{ij}} \mathrm{u}_{\mathrm{it}}+\mathrm{e}_{\mathrm{it}}
$$


- The mixed partial adjustment model-spatial Durbin model, PAM-SDM:

$$
\begin{aligned}
\mathrm{Y}_{\mathrm{it}}-\mathrm{Y}_{\mathrm{it}-1}= & \rho \sum_{\mathrm{j} \neq \mathrm{i}}^{\mathrm{n}} \omega_{\mathrm{ij}}\left(\mathrm{Y}_{\mathrm{jt}}-\mathrm{Y}_{\mathrm{jt}-1}\right)+\delta\left(\mathrm{Y}_{\mathrm{it}}^{*}-\mathrm{Y}_{\mathrm{it}-1}\right)+\sum_{\mathrm{k}=1}^{\mathrm{K}-1} \delta_{\mathrm{k}}\left(\mathrm{Y}_{\mathrm{it}}^{*}-\mathrm{Y}_{\mathrm{it}-1}\right) \mathrm{g}_{\mathrm{k}} \\
& \lambda \sum_{\mathrm{j} \neq \mathrm{i}}^{\mathrm{n}} \omega_{\mathrm{ij}}\left(\mathrm{Y}_{\mathrm{it}}^{*}-\mathrm{Y}_{\mathrm{it}-1}\right)+\sum_{\mathrm{k}=1}^{\mathrm{K}-1} \lambda_{\mathrm{k}} \sum_{\mathrm{j} \neq \mathrm{i}}^{\mathrm{n}} \omega_{\mathrm{ij}}\left(\mathrm{Y}_{\mathrm{jt}}^{*}-\mathrm{Y}_{\mathrm{jt}-1}\right) \mathrm{g}_{\mathrm{k}}+\mathrm{e}_{\mathrm{it}}
\end{aligned}
$$

Finally, it should be considered that we are mixing information from a (large and heterogeneous) group of companies, which were observed over a number of time periods. This is a panel dataset and, as such, we are going to introduce unobserved individual and time effects in the right-hand side of equations (1) to (5). The estimation of panel data models, with or without spatial effects, is now a routine task that can be undertaken using standard software, such as R, STATA, MATLAB, etc., (see Baltagi, 2013, or LeSage and Pace, 2009, for general textbooks and Lee and Yu, 2010a and b, Lee and Yu, 2012 or Elhorst, 2014 for more specialized references).

\section{Data for the analysis}

We use a sample of Spanish manufacturing SMEs companies located in 12 provinces (Nuts III units according to Eurostat) along the Spanish Mediterranean Axis (SMA). This geographical area accounts for more than $40 \%$ of total population (approximately 19 million inhabitants), and concentrate more than $40 \%$ of Spanish economic activity in less than $20 \%$ of the country territory. Figure 1 show the SMA area divided in administrative provinces.

Data come from the database Sistema de Análisis de Balances Ibéricos (SABI). The sample is composed of 12,444 companies (NACE codes 1000 to 3320), for the period 2006-2012; their geographical distribution appears in Figure 1. All companies with more than 250 employees and without employees were excluded. We analyse reduced size companies which are more sensible to peer effects (Leary and Robert, 2014). The sample represents, approximately, $20 \%$ of all manufacturing companies located in SMA, with a number of employees between 1 and 250 according to census of Spanish companies (Directorio Central de Empresas, DIRCE, provided by the Spanish National Institute of Statistics), at the end of 2012. The number of employees in our sample, in 
2012, is approximately 230,000 that represent almost $15 \%$ of total employees in Spanish industrial sector (see Table A1 in the Appendix for the composition of the sample in terms of industrial sectors). The location of a company is defined by the geographical coordinates of its headquarters. Corporate headquarters are the centers where the main financial decisions of the company are taken and where, basically, interaction with other agents takes place (Pirinsky and Wang, 2010); thus, this is not a restriction for our work.

Using this information, three financial ratios representative of three financial dimensions have been obtained for each company (Soboh et al., 2009). The first two pertain to liquidity and indebtedness and measure the ability of a firm to fulfil (pay) its current obligations as they arise, and the nature of any financing equity. The third is related to the profitability and evaluates the ability of a company to generate earnings. Liquidity is measured by the Current ratio (henceforth CU) computed as Short Term Assets divided by Short Term Liabilities. Indebtedness is evaluated by the Debt Equity ratio (henceforth DE) calculated as Total Liabilities over Total Assets. Finally, profitability is evaluated by the Profitability Ratio (henceforth PR) which is Net Operating Income divided by Total Assets. These are the $Y_{i t}$ variables in equations (1) to (5). For each ratio, and according to Lev (1969), the objective is proxied as the corresponding sectoral average in the previous year: $\mathrm{Y}_{\mathrm{it}}^{*}=\sum_{\mathrm{i}=1}^{\mathrm{n}} \mathrm{Y}_{\mathrm{it}-1} / \mathrm{n}$.

-Insert Figure 1

In Section 2 we have introduced the problem of nonlinearities in the basic PAM model, pointing to six main factors with capacity to modify the adjustment process in the financial ratios. These factors are defined and coded in Table 1.

Insert Table 1

Note that the set of companies included in group $d_{i t, 1}$, does not deviate too much from the target (which is, as indicated, the average of the industry in the previous period). The second group in this variable, $\mathrm{d}_{\mathrm{it}, 2}$, corresponds to companies that are far 
from the target but below it, whereas the companies in the third group, $\mathrm{d}_{\mathrm{it}, 3}$, are also far from the target but above it.

Table 2 shows a descriptive analysis of the main variables included in the study. The companies in the sample are of small size (56.2\%), with low technology (45.6\%). Mostly of companies are located in Catalonia (51.5\%), operate in local markets (62.3\%) and only a small percentage (6.9\%) are below 10 years old. Those percentages are congruent with the official Spanish census (DIRCE) corresponding to the same sector and Autonomous Communities. With respect to the structure by subsector, detailed information is provided in the supplementary Table A.

Insert Table 2

We have computed the financial ratios (CU, DE, PR) for the different categories of size, technological intensity, region, market and age. There are only small differences between the means corresponding to each group. With respect to the size factor, indebtedness (DE) decreases with size whereas liquidity (CU) goes in the other direction. A similar situation is produced in relation to technological intensity. The ratio DE decreases with the technological content, but CU tends to increase. These results are in accordance with previous literature that highlights the better situation, in terms of lower debt and higher profitability and liquidity, of larger and high-tech companies (Wu and Ho, 1997; Gallizo and Salvador, 2003). Current ratio (CU) grows up in companies with export activity, while DE ratio decreases for the same group. This result is also in accordance with previous studies which relate the international character of the firm with greater risks associated to its activity. In this case, firms tend to adopt more conservative financial policies, decreasing external indebtedness and maintaining more volume of short term assets (Pacheco, 2016). The CU ratio increases with the age of the company, but the DE ratio decreases. However, the PR ratio does not have a clear pattern. Berger and Udell (1998) study the evolution and types of financing as firms become older. These authors find that newcomer companies resort to more formal finance resources, raising bank indebtedness and other types of financial intermediaries. As firm gets older, accumulated retained earnings become an important source of funding in itself, as well as providing reassurance for potential external funders in relation to firm performance. 


\section{Empirical results}

\subsection{Exploratory Spatial Data Analysis}

This section focuses on the spatial structure on the explained variable $\left(Y_{i t}-Y_{i t-1}\right)$ for the three ratios (CU, DE, PR). In first place, we use the classical Moran I test (Moran, 1948) and its spatio-temporal version STMI (López et al., 2011) for different connectivity criteria to check for global dependence among the companies in space and time. Then, we obtain the Gi Getis-Ord statistic (Getis and Ord, 1992) to identify local spatial patterns. As indicated in Section 3, this analysis is conditional on the $\mathrm{W}$ contiguity matrix for which we try two different approaches based on the distance between the headquarters: (i) the great-circle and (ii) the nearest-neighbors criterion. Specifically, according to the first approach, two companies are considered connected if they are separated by a distance less than $5 \mathrm{Km}$ or $10 \mathrm{Km}\left(\mathbf{W}_{\mathbf{5 k m}} ; \mathbf{W}_{\mathbf{1 0 k m}}\right)$; using the second criterion, the group of neighbors of each company is made of the 25 or 50 nearest companies $\left(\mathbf{W}_{\mathbf{2 5 n}} ; \mathbf{W}_{\mathbf{5 0 n n}}\right)$.

The four matrices reflect a very localized network of dependencies, which is in accordance with the "kept an eye" principle on your competitors. Moreover, the local specification of $\mathrm{W}$ help us to reduce the bias arising from the boundary effect caused by the existence of companies located in the West border of the SAM that interact with companies not in our sample (because they are not located in the SAM). The four matrices are exogenous, assuming that the location of the companies is given, and are of binary type, where 1 indicates proximity and 0 non-proximity. Afterwards, the matrices have been row-standardized in order that each row adds to one.

Table 3 shows the standardized Moran I and STMI statistics for each financial ratio, year and connectivity matrix. Let us remind that the null hypothesis of Moran I is no spatial dependence for the data under scrutiny and that null hypothesis of the second statistic is no spatio-temporal dependence. Under the null hypothesis, the limit distribution of both tests is standard normal. We find strong evidence of spatial dependence in the case of the PR ratio, for all periods considered, whereas the evidence is weaker in the case of CU and DE. In all cases, the STMI shows clear indications of spatial-temporal spatial autocorrelation. Let us note that the STMI takes the maximum value, in the three ratios, for the matrix $\mathbf{W}_{\mathbf{5 0 n n}}$ and, therefore, we consider this matrix as the suitable candidate in the confirmatory analysis that follows. 
Figure 2 shows the results of the local Gi statistics for the three ratios for the period 2012-2011 using $\mathbf{W}_{\mathbf{5 0 n n}}$. A clear regional pattern emerges from them. For PR and CU we find big High-High clusters (red dots in Figure 2) of companies located in the metropolitan area of Barcelona, in the North of the SAM; the red dots extend also to other Catalonian provinces, like Lleida or Girona. The contrary occurs in the case of indebtedness, DE, where the blue dots, Low-Low clusters, dominate in the case of Catalonia. Southern provinces of the SAM are characterized by Low-Low clusters in CU and PR ratios and High-High clusters in DE. The tendency accentuates in this direction.

-Insert Figure 2--------------------

These findings refer us to the impact of unobservable effects related of institutional and environmental factors. In fact, the Spanish case is characterized by a highly decentralized public administration, where the regions (Autonomous Communities, in this case) share, or even lead, a lot of public policies with the national Government (Tomas, 2015). Catalonia is one of the historical Spanish nationalities, which enjoys some benefits in relation to other territories.

\subsection{Confirmatory analysis}

We begin by estimating the basic PAM model extended with a set of multiplicative dummy variables to account for nonlinearities. We include the spatial lag of the gap $\left(\mathrm{Y}_{\mathrm{it}}^{*}-\mathrm{Y}_{\mathrm{it}-1}\right)$ for each ratio in the right hand side of our baseline model which, in fact, is a SLX equation (we omit the inclusion of the spatial lags of the multiplicative dummy variables). Vega and Elhorst (2015) advocate for this specification as a more efficient way to begin with the discussion of a spatial model. Therefore, the equation is:

$$
\begin{aligned}
& \mathrm{Y}_{\mathrm{it}}-\mathrm{Y}_{\mathrm{it}-1}=\delta\left(\mathrm{Y}_{\mathrm{it}}^{*}-\mathrm{Y}_{\mathrm{it}-1}\right)+\delta^{\mathrm{L}} \sum_{\mathrm{j}=1}^{\mathrm{n}} \omega_{\mathrm{ij}}\left(\mathrm{Y}_{\mathrm{it}}^{*}-\mathrm{Y}_{\mathrm{it}-1}\right)+\sum_{\mathrm{k}=2}^{3} \delta_{\mathrm{dk}}\left(\mathrm{Y}_{\mathrm{it}}^{*}-\mathrm{Y}_{\mathrm{it}-1}\right) \mathrm{d}_{\mathrm{it}, \mathrm{k}}+ \\
& +\sum_{\mathrm{k}=2}^{3} \delta_{\mathrm{sk}}\left(\mathrm{Y}_{\mathrm{it}}^{*}-\mathrm{Y}_{\mathrm{it}-1}\right) \mathrm{s}_{\mathrm{it}, \mathrm{k}}++\sum_{\mathrm{k}=2}^{4} \delta_{\mathrm{tk}}\left(\mathrm{Y}_{\mathrm{it}}^{*}-\mathrm{Y}_{\mathrm{it}-1}\right) \mathrm{t}_{\mathrm{it}, \mathrm{k}}+\sum_{\mathrm{k}=2}^{4} \delta_{\mathrm{rk}}\left(\mathrm{Y}_{\mathrm{it}}^{*}-\mathrm{Y}_{\mathrm{it}-1}\right)_{\mathrm{it}, \mathrm{k}}+ \\
& +\sum_{\mathrm{k}=2}^{4} \delta_{\mathrm{mk}}\left(\mathrm{Y}_{\mathrm{it}}^{*}-\mathrm{Y}_{\mathrm{it}-1}\right) \mathrm{m}_{\mathrm{it}, \mathrm{k}}+\sum_{\mathrm{k}=2}^{3} \delta_{\mathrm{ak}}\left(\mathrm{Y}_{\mathrm{it}}^{*}-\mathrm{Y}_{\mathrm{it}-1}\right) \mathrm{a}_{\mathrm{it}, \mathrm{k}}+\mathrm{e}_{\mathrm{it}}
\end{aligned}
$$


Where $\left\{\omega_{i j} ; i, j,=1, \ldots, n\right\}$ denotes the $(i, j)$ term of the $\mathbf{W}_{\mathbf{5 0 n n}}$ contiguity matrix. Note that the reference group includes micro-companies whose gap lies between the $10^{\text {th }}$ and $90^{\text {th }}$ percentiles, using low level of technology, located in the region of Murcia, without internationalization and between 5-10 years olds. Therefore, if a coefficient $\delta_{\text {hk }}$ ( $\mathrm{h} \in \Omega=\{\mathrm{d}, \mathrm{s}, \mathrm{t}, \mathrm{r}, \mathrm{m}, \mathrm{a}\}, \mathrm{k}=1, \ldots, \mathrm{n}_{\mathrm{k}}$ ) appears with a positive estimate(resp. negative) and significantly different from 0 , this points that the corresponding group has more (resp. less), speed of convergence with respect to the reference group. The main results of the panel estimation appear in Table 4.

The LR tests at the bottom of Table 4 corroborate the importance of controlling for individual and time effects. We should remember that the null hypothesis of the LR tests is that there are no unobserved effects in the equation whereas the alternative hypothesis states that there are unobserved effects both in the cross-sectional and in the time dimension (Baltagi, 2013). The three tests reject the null hypothesis (a similar conclusion is reached when using these tests only for the time or the cross-sectional dimension). Moreover, the Hausman tests indicate that the nature of the unobserved effects is fixed: In other words, the unobservables are correlated with the error term of the equation. The random effects model should be thus discarded.

Insert Table 4

The estimates corresponding to the two-way fixed effects model for the three ratios appear in the top panel of Table 4. Overall, the results are quite sensible. We find significant and positive adjustment coefficients $(\delta)$ for the three financial ratios, which constitutes a strong support for the PAM hypothesis; moreover, they are roughly in line with previous results in the literature (Gallizo et al., 2008; Mate et al., 2012). The financial gap of neighbor companies, $\delta^{\mathrm{L}}$, has a negative and significant effect on the financial adjustment of each company. In other words, a company surrounded by companies with great unbalances has weaker incentives to adjust its financial ratios. In addition, the suspicions about the presence of nonlinearities in the adjustment process are confirmed. The Chow tests show significant differences of most of the factors included in models.

Regarding the distance to the gap, the speed of adjustment is greater for companies with CU and PR ratios below, and far, from the targets than for companies whose ratios 
are almost at the target. However, the situation is not symmetric. The speed of adjustment is lower for companies with DE ratios far and above the targets. Companies with a high level of debt will try to reduce it because of the increasing costs associated with the disequilibrium (Faukelner et al., 2010; Aybar-Arias et al., 2012). Finally, companies with poor results in terms of profitability (PR) must improve their performance to keep market share whereas those companies more efficient than the average (in group 3) have few incentives to decelerate the movement towards the average. Despite the lower speed of adjustment in this case, market forces press the PR ratios. Higher PR ratios, above form the target, will attract more competitors sharing the market quote and reducing profits (Davis and Peles, 1993).

The size of the company is also an element to be considered. The results show significant and negative estimates, for the three ratios, in the case of small- or mediumto large-sized companies. Therefore, micro-sized companies have more incentives to readjust their financial structure. Davis and Peles (1993) and Wu and Ho (1997) obtained similar results for this variable stressing the importance, especially for small companies, of being as near as possible to the optimum. Small companies have stronger incentives to correct the disequilibrium because their high out of equilibrium costs (Davis and Peles, 1993). In addition, SMEs have more flexibility and less bureaucracy to reach the target values quicker than large firms (Wu and Ho, 1997). The pressure for large companies is weaker, their incentives are lower and therefore their reactions are produced more slowly.

Regarding the technological intensity, in general terms, the estimates of the dummies tend to be positive, which means that the speed of adjustment increases as the technological content of the activity rises. Gallizo et al. (2008) find the same effect, concluding that the need for greater resource availability for the group of high-tech companies forces them to readjust their financial ratios more quickly.

The same can be said in relation to the trade patterns of the company. Firms working mainly for international markets face higher agency costs in comparison with firms more involved in domestic markets (Pacheco, 2016). Therefore, international firms have more incentives to adjust their financial ratios to the targets as faster as possible in order to avoid additional costs. Finally, we get that the age plays a relevant role shaping the non-linearities of this adjustment process. According to our expectations, we find that older firms have fewer incentives to adapt their financial ratios towards target values in comparison with newcomers (Cole, 2013). 
The specification tests, LM and STMI, that appear at the bottom of Table 4 test for the omission of spatial interaction elements in the PAM models of (6). The conclusion that emerges from these tests is clear: the extended PAM equations are wrongly specified because of additional omitted spatial effects. The next step is to consider the most suitable spatial structure for our PAM.

The Lagrange Multipliers, LM, are all very significant and do not offer useful clues to guide the specification (similar results are obtained with the robust $\mathrm{LM})^{1}$. On this point, LeSage and Pace (2009) recommend starting the discussion using the spatial Durbin model of (5), which nests both the SLM and the SEM models. Two Likelihood Ratio (LR) tests can then be used to test the PAM-SDM (this is the alternative hypothesis) against the PAM-SEM or the PAM-SLM, respectively, in the null (Burridge 1981). If both null hypotheses are rejected, then the PAM-SDM of (7) is the logical selection.

$$
\begin{aligned}
& \left(\mathrm{Y}_{\mathrm{it}}-\mathrm{Y}_{\mathrm{it}-1}\right)=\rho \sum_{\mathrm{j} \neq \mathrm{i}}^{\mathrm{n}} \omega_{\mathrm{ij}}\left(\mathrm{Y}_{\mathrm{it}}-\mathrm{Y}_{\mathrm{it}-1}\right)+\delta^{\mathrm{L}} \sum_{\mathrm{j} \neq 1}^{\mathrm{n}} \omega_{\mathrm{ij}}\left(\mathrm{Y}_{\mathrm{it}}^{*}-\mathrm{Y}_{\mathrm{it}-1}\right)+\sum_{\mathrm{k}=2}^{3} \delta_{\mathrm{dk}}\left(\mathrm{Y}_{\mathrm{it}}^{*}-\mathrm{Y}_{\mathrm{it}-1}\right) \mathrm{d}_{\mathrm{it}, \mathrm{k}}+\sum_{\mathrm{k}=2}^{3} \delta_{\mathrm{sk}}\left(\mathrm{Y}_{\mathrm{it}}^{*}-\mathrm{Y}_{\mathrm{it}-1}\right)_{\mathrm{it}, \mathrm{k}} \\
& +\sum_{\mathrm{k}=2}^{4} \delta_{\mathrm{tk}}\left(\mathrm{Y}_{\mathrm{it}}^{*}-\mathrm{Y}_{\mathrm{it}-1}\right) \mathrm{t}_{\mathrm{it}, \mathrm{k}}+\sum_{\mathrm{k}=2}^{4} \delta_{\mathrm{rk}}\left(\mathrm{Y}_{\mathrm{it}}^{*}-\mathrm{Y}_{\mathrm{it}-1}\right) \mathrm{r}_{\mathrm{it}, \mathrm{k}}+\delta\left(\mathrm{Y}_{\mathrm{it}}^{*}-\mathrm{Y}_{\mathrm{it}-1}\right)+\delta^{\mathrm{L}} \sum_{\mathrm{j} \neq \mathrm{i}}^{\mathrm{n}} \omega_{\mathrm{ij}}\left(\mathrm{Y}_{\mathrm{it}}^{*}-\mathrm{Y}_{\mathrm{jt}-1}\right)+\sum_{\mathrm{k}=2}^{3} \delta_{\mathrm{dk}}^{\mathrm{L}} \sum_{\mathrm{j} \neq \mathrm{i}}^{\mathrm{n}} \omega_{\mathrm{ij}}\left(\mathrm{Y}_{\mathrm{it}}^{*}-\mathrm{Y}_{\mathrm{it}-1}\right) \mathrm{d}_{\mathrm{it}, \mathrm{k}} \\
& +\sum_{\mathrm{k}=2}^{3} \delta_{\mathrm{sk}}^{\mathrm{L}} \sum_{\mathrm{j} \neq \mathrm{i}}^{\mathrm{n}} \omega_{\mathrm{ij}}\left(\mathrm{Y}_{\mathrm{it}}^{*}-\mathrm{Y}_{\mathrm{it}-1}\right) \mathrm{sit}_{\mathrm{it}, \mathrm{k}}+\sum_{\mathrm{k}=2}^{4} \delta_{\mathrm{tk}}^{\mathrm{L}} \sum_{\mathrm{j} \neq \mathrm{i}}^{\mathrm{n}} \omega_{\mathrm{ij}}\left(\mathrm{Y}_{\mathrm{it}}^{*}-\mathrm{Y}_{\mathrm{it}-1}\right) \mathrm{t}_{\mathrm{it}, \mathrm{k}}+\sum_{\mathrm{k}=2}^{4} \delta_{\mathrm{rk}}^{\mathrm{L}} \sum_{\mathrm{j} \neq \mathrm{i}}^{\mathrm{n}} \omega_{\mathrm{ij}}\left(\mathrm{Y}_{\mathrm{it}}^{*}-\mathrm{Y}_{\mathrm{it}-1}\right) \mathrm{r}_{\mathrm{it}, \mathrm{k}}+\mathrm{e}_{\mathrm{it}}
\end{aligned}
$$

Table 5 depicts the estimated PAM-SDM models for the three financial ratios, including the corresponding LR tests at the bottom of the Table. This time, the conclusion is clear: the PAM-SDM cannot be rejected in favor of either the PAM-SLM or the PAM-SEM model. Overall, the results are satisfactory and very much in line with those presented in Table 4. Let us note that there are no symptoms of remaining spatial and/or temporal dependence in the errors of these estimates, according the STMI tests.

Insert Table 5

The main difference lies in the measures of goodness-of-fit to the data for the three financial ratios. In addition, we get positive and significant spatial interaction

\footnotetext{
${ }^{1}$ Moreover, we exclude the more general Cliff-Ord model, with spatial structure both in the mean equation and in the errors because their estimates offer clear symptoms of over-specification (where the spatial structure in the errors offsets, in the opposite sense, the spatial structure in the mean equation).
} 
coefficients $(\rho)$ related to the dependent variable $\left(Y_{i t}-Y_{i t-1}\right)$. From a theoretical perspective, this term is related to the actions taken by companies in the neighborhood. That means that a company i will receive a positive shock on its adjustment coefficient if its neighbors are adjusting their financial ratios. Nevertheless, this effect is lower (0.05, 0.072 and 0.185 for CU, DE and PR respectively) than the effect associated to the characteristics of the neighbors (0.555, 0.445 and 0.616 for $\mathrm{CU}, \mathrm{DE}$ and $\mathrm{PR}$ respectively). Therefore, regarding the channels of interaction between firms, our findings give more relevance to the characteristics of the neighborhood than to the decisions taken by companies in the neighborhood. This result seems to contradict the findings in Leary and Roberts which give more relevance to the decisions (2014).

\subsection{Direct and indirect effects on the PAM-SDM estimates}

The structure of the PAM-SDM model in (7) implies that there are spatial spillovers, which places some limitations on interpreting the estimates. Let us use an example. In a linear model without spatial effects, such as the following (if we add an intercept, nothing changes) $y_{i}=\beta x_{i}+u_{i} ; i=1, \ldots, n$, the slope $\beta$ is the partial derivative of the endogenous variable, $y_{i}$, with respect to the exogenous variable, $x_{i}$, which coincides with the impact of a unitary change of $x_{i}$, on $y_{i}$. Note that this measure is the same for every observation in the sample.

This is not necessarily true if there are spatial elements in the equation, as is the case of a simple SDM version of the previous model, $y_{i}=\rho \sum_{j \neq i}^{n} \omega_{i j} y_{i}+\beta x_{i}+\beta^{L} \sum_{j \neq i}^{n} \omega_{i j} x_{i}+e_{i}$. First, we should write the model in matrix notation: $\mathbf{y}=\rho \mathbf{W y}+\mathbf{Z} \theta+\mathrm{e}$, where $\mathrm{y}$ and $\mathrm{x}$ are the (nx1) vectors of observations of variables $y$ and $x ; \mathbf{Z}=[\mathrm{x}, \mathbf{W x}]$ is a (nx2) matrix of observations of $x$ or lags of $x ; \theta=\left[\beta, \beta^{L}\right]^{\prime}$ is a $(2 x 1)$ vector of parameters; and e is the (nx1) vector of error terms. Then, we obtain the reduced form of the SDM equation as $\mathrm{y}=(\mathrm{I}-\rho \mathbf{W})^{-1} \mathbf{Z} \theta+(\mathrm{I}-\rho \mathbf{W})^{-1} \mathrm{e}$.

The impact of a unitary change in the $x$ variable of the i-th company (that is, the partial derivative measured evaluated in this point $\left.(\partial \mathrm{y} / \partial \mathrm{x})_{\mathrm{i}}\right)$ is: 


$$
(\partial y / \partial x)_{i}=(I-\rho \mathbf{W})^{-1}\left(\beta \times \tau_{i}+\beta^{L} \times \mathbf{W}_{\tau_{i}}\right)
$$

where $\tau_{\mathrm{i}}$ is a (nx1) vector of zeros except the $\mathrm{i}$-th term which is a one. Note that $(\partial y / \partial x)_{i}$ is also a (nx1) vector, possibly, with all elements different from zero. The impact of a unitary change of the exogenous variable of the i-th company on the endogenous variable of the same company appears in the i-th term of this vector; the other (n-1) terms reflect the impact on the endogenous variable but of different companies. Note that these impacts on other companies are zero in the linear model.

The differences are due to the spatial spillovers (similar results are obtained for other spatial models; see Elhorst, 2014) and led to LeSage and Pace (2009, p. 74) to distinguish between the so-called "Direct," "Indirect" and "Total” effects of a unitary change on an exogenous variable, somewhere in the space (or in the network of companies). The direct effect measures the impact of a unitary change on a given exogenous variable, in the i-th location (company in our case) on the endogenous in the same location (company). The indirect effect is the impact of the same change, but on locations (companies) different from the i-th, and the total effect is the sum of the two. These effects, probably, will vary from location to location (company to company) which means too much information. In order to abridge the discussion of results, it is usual to present basic indicators such as the mean values of the corresponding effects. LeSage and Pace advise that the researcher should focus on these effects, rather than on the estimated values of the parameters, in order to attain a correct reading of the estimated spatial model. The results for the PAM-SDM model of (7) are included in Table 6.

The direct effects for the variables related to the gap $(\delta)$ are positive and significant in the three financial ratios, but not the indirect effects. The consequence is that the total effects are significantly smaller than those obtained using the non-spatial model (Table 4). Therefore, a company, surrounded by a group of companies whose ratios are further from their targets, will have a negative effect on its own adjustment process. In other words, this company will receive few incentives from its environment to readjust the financial ratios.

The terms associated with multiplicative dummy variables of the gap make evident the interaction in our dataset. The estimated direct effects are similar to the point 
estimates in Table 5 but we also obtain a set of very important indirect effects. Our interpretation is that companies are pushed to move in the correct direction, first, by purely internal mechanisms (identified with the direct effects), and this impulse is strengthened if the neighboring companies are in a similar position.

Insert Table 6

Regarding the size of the company, the direct effects are in line with those in Table 5 and the indirect effects are also relevant. According to these results, being located in a milieu characterized by small- and medium-sized companies (in contrast with that dominated by micro-firms) stimulates the company to adjust faster its financial ratios.

Similar results are obtained in relation to technology. The direct effects are in line with the estimates in Table 5, showing that a high-tech company tends to react faster to external shocks than other companies, whereas the indirect effects, smaller, tend to be positive which means that a high tech neighborhood favors the speed up of the adjustment process of the companies present there. The region where the company is located also influences this adjustment process but the pattern estimated is not clear; obviously Murcia is in the worst position. The internationalization of the company increases the speed of adjustment due to the higher risk associated to these markets. This result is strengthened if the other companies in the neighborhood are also involved in import/export activities. Finally, the age of the company appears, as expected, with negative estimates for the direct and indirect effects, highlighting the break between newcomers and mature old stablished firms.

\section{Discussion and Conclusions}

This paper demonstrates that the financial decisions and the characteristics the companies of the milieu where is located a company strongly influences the financial behavior, especially, of SMEs. We separate from the study of Leary and Robert (2014) in taking into account the geographical proximity of peers as an explicit factor conditioning the reaction of companies to unbalances in their financial structure. Our main hypothesis is that geographical proximity favors informational flows among economic agents (Carbó et al., 2003; Degryse and Ongena, 2005), encouraging more efficient responses in the financial sphere. We find that the characteristics of the neighborhood is a more relevant factor that the decisions taken by the neighbors. These results extend those obtained by Leary and Roberts (2014) under the assumption of no spatial interaction. 
We also find strong non-linearities in the adjustment process in function of several firms' characteristics. These results coincide with previous studies (Lee and $\mathrm{Wu}, 1988$; Gallizo et al., 2008; Mate et al., 2012).

In particular, we corroborate the existence of a so-called herd behavior in the case of SMEs, which modulates the first impulse, inner, of the company. Thus, there are particular environments that favor reactive companies. Responsive companies are surrounded by environments with relative young and medium-sized companies with high tech activities acting in international markets. This general result does not depend on the financial dimension considered. Our findings, the same as Leary and Roberts (2014), also point to questions related to learning and reputation as one of the causes of this proximity effect. We add that the impact of these effects will be accentuated because of geographical proximity that favors informational flows and reduces the consequences of informational asymmetries (Degresy and Ongena, 2005).

Finally, we have to admit that this paper represents only a new step in order to better understand the interactions produced in the financial sphere of industrial companies. It is clear that further contributions are necessary to characterize the mechanisms and the dynamics that promote the interactions among geographically clustered companies. 


\section{Appendix}

Table A1: Number of companies by CNAE code (2-digit) in Spain, in the SMA area and in our sample.

\begin{tabular}{lccccc}
\multicolumn{1}{c}{ CNAE (2 digit) } & Total $^{\dagger}$ & SMA $^{\ddagger}$ & Sample & \%(Total) & \%(SMA) \\
10 Manuf. of food products & 24171 & 7843 & 1250 & $5.2 \%$ & $15.9 \%$ \\
11 Manuf. of beverages & 5025 & 954 & 192 & $3.8 \%$ & $20.1 \%$ \\
12 Manuf. of tobacco products & 47 & 3 & 1 & $2.1 \%$ & $33.3 \%$ \\
13 Manuf. of textiles & 6437 & 2779 & 784 & $12.2 \%$ & $28.2 \%$ \\
14 Manuf. of wearing apparel & 9710 & 2701 & 307 & $3.2 \%$ & $11.4 \%$ \\
15 Manuf. of leather and related products & 4707 & 2033 & 447 & $9.5 \%$ & $22.0 \%$ \\
16 Manuf. of wood and of products of wood & 12707 & 3513 & 623 & $4.9 \%$ & $17.7 \%$ \\
17 Manuf. of paper and paper products & 1870 & 824 & 308 & $16.5 \%$ & $37.4 \%$ \\
18 Printing and reproduction of recorded media & 15600 & 4029 & 856 & $5.5 \%$ & $21.2 \%$ \\
19 Manuf. of coke and refined petroleum products & 19 & 6 & 5 & $26.3 \%$ & $83.3 \%$ \\
20 Manuf. of chemicals and chemical products & 3715 & 1621 & 617 & $16.6 \%$ & $38.1 \%$ \\
21 Manuf. of basic pharmaceutical products & 375 & 129 & 45 & $12.0 \%$ & $34.9 \%$ \\
22 Manuf. of rubber and plastic products & 5123 & 2224 & 770 & $15.0 \%$ & $34.6 \%$ \\
23 Manuf. of other non-metallic mineral products & 10397 & 3952 & 738 & $7.1 \%$ & $18.7 \%$ \\
24 Manuf. of basic metals & 1411 & 442 & 222 & $15.7 \%$ & $50.2 \%$ \\
25 Manuf. of fabricated metal products ... & 39245 & 12246 & 2077 & $5.3 \%$ & $17.0 \%$ \\
26 Manuf. of computer, electronic ... & 2796 & 841 & 182 & $6.5 \%$ & $21.6 \%$ \\
27 Manuf. of electrical equipment & 2441 & 867 & 283 & $11.6 \%$ & $32.6 \%$ \\
28 Manuf. of machinery and equipment n.e.c. & 6181 & 2554 & 917 & $14.8 \%$ & $35.9 \%$ \\
29 Manuf. of motor vehicles, ... & 2005 & 641 & 186 & $9.3 \%$ & $29.0 \%$ \\
30 Manuf. of other transport equipment & 869 & 250 & 39 & $4.5 \%$ & $15.6 \%$ \\
31 Manuf. of furniture & 15369 & 4626 & 626 & $4.1 \%$ & $13.5 \%$ \\
32 Other manufacturing & 9808 & 2480 & 333 & $3.4 \%$ & $13.4 \%$ \\
33 Repair and installation of machinery ... & 10575 & 2577 & 636 & $6.0 \%$ & $24.7 \%$ \\
TOTAL: & $\mathbf{1 9 0 6 0 3}$ & $\mathbf{6 0 1 3 5}$ & $\mathbf{1 2 4 4 4}$ & $\mathbf{6 . 5 \%}$ & $\mathbf{2 0 . 7 \%}$ \\
† Number of companies in Spain with CNAE code 1000-3300. & & & & & \\
₹ Number of companies in the Autonomous Communities of Catalonia, Valencia, Murcia and Andalusia with CNAE code & & & & & \\
1000-3320. & & & & & \\
Source: DIRCE www.ine.es & & & &
\end{tabular}




\section{REFERENCES}

Aybar-Arias, C., Casino-Martínez, A., and López-Gracía, J. (2012) On the adjustment speed of SMEs to their optimal capital structure. Small Business Economics, 39(4), 977-996.

Baltagi, B. (2013): Econometric Analysis of Panel Data, 5th Edition. Wiley, New York.

Berger, A. N. and Udell, G. F. (1998) The economics of small business finance: the roles of private equity and debt markets in the financial growth cycle, Journal of Banking and Finance, 22, 613-73.

Bonaccorsi, E. and Gobbi, G. (2001) The changing structure of local credit markets: Are small business special? Journal of Banking and Finance, 25, 2209-2237.Brown, L.D., Call, A.C., Clement, M.B. and Sharp, N.Y. (2014) Inside the 'Black Box' of Sell-Side Financial Analysts, Journal of Accounting Research, 53 (1), 1-47.

Burridge, P. (1981). Testing for a Common Factor in a Spatial Autoregression Model. Environment and Planning A, 13, 795-800.

Carbó, S., Humphrey, D., and Rodriguez-Dez, F. (2003) Deregulation, bank competition and regional growth. Regional Studies, 37(3), 227-237.

Carbó, S., López, R. and Rodríguez, F. (2007) Financial Innovations in Banking: Impact on Regional Growth, Regional Studies, 41(3) 311-326.

Carreira, C. and Silva, V. (2010) No deep pockets: some stylised empirical results on firms’ financial constraints, Journal of Economic Surveys, 24(4), 731-753.

Chen, C. R., and Ainina F. (1994) Financial Ratio Adjustment Dynamics and Interest Rate Expectations, Journal of Business Finance \& Accounting, 21(8), 1111-1126.

Cole, 2013 What Do We Know about the Capital Structure of Privately Held US Firms? Evidence from the Surveys of Small Business Finance

Corrado, L. and B. Fingleton (2012) Where is the economics in spatial econometrics? Journal of Regional Science, 52 210-239

Davis, G., and Greve, H.R. (1997) Corporate elite structures and governance Changes in the 1980 s. American Journal of Sociology, 103(1).

Davis, H. and Peles Y. (1993) Measuring Equilibrating Forces of Financial Ratios, The Accounting Review, 68, 725-747.

Degryse, H., and Ongena, S. (2005) Distance, lending relationships, and competition. The Journal of Finance, 60(1), 231-266. 
Du X. and Xiu, Z., (2009) Institutional Environment, Blockholder Characteristics and Ownership concentration in China. China Journal of Accounting Research, 2, 27-57. Elhorst, P. (2014) Spatial Econometrics. From Cross-Sectional Data to Spatial Panels. Berlin Springer.

Fan, J., Wong, T.J. and Zhang, T., (2009) Organizational structure as a decentralization device: Evidence from corporate pyramids. Hong Kong University of Science and Technology Working Paper.

Faulkender, M., Flannery, M; Watsonhankins, K. and Smith M. (2012) Cash flows and leverage adjustments. Journal of Financial Economics, 103, 632-646

Fernández, J. and Maudos, J. (2009) Regional financial development and bank competition: effects on firms' growth, Regional Studies, 43,211-228.

Frank, M.Z., and Goyal V.K. (2009) Capital structure decisions: Which factors are reliably important? Financial Management, 38, 1-37.

Gallizo, J.L., and Salvador, M. (2003) What Factors Drive and which Act as a Brake on the Convergence of Financial Statements in EMU Member Countries?, Review of Accounting \& Finance, 1(4), 49-68.

Gallizo, J.L., Gargallo P. and Salvador, M. (2008) Multivariate Partial Adjustment of Financial Ratios: A Bayesian Hierarchical Approach, Journal of Applied Econometrics, 23(1), 46-64.

Gao, W., Ng, L. and Wang, Q. (2013) Does corporate headquarters location matter for firm capital structure?. Financial Management, 40(1), 113-138.

Getis and Ord, J.K. (1992) The analysis of spatial association by use of distance statistics, Journal of Geographical Analysis, 24: 189-206.

Graham, J. and Harvey, C. (2011) The theory and practice of corporate finance: evidence from the field, Journal of Financial Economics, 60, (2-3), 187-243

Granovetter, M. (1985) Economic action and social structure: The problem of embeddedness. American Journal of Sociology, 91(3).

Halleck Vega, S. and J.P. Elhorst (2015) The SLX model. Journal of Regional Science, 55, 339-363.

Harris, R., J. Moffat and V. Kravtsova (2011) In search of W. Spatial Economic Analysis, 6 249-270.

Joong, I. and Kang, Y. (2015) Peer Effects in Capital Structure Adjustments. 28th Australasian Finance and Banking Conference 2015 
Knyazeva, A. and Knyazeva, D. (2012) Does being your bank's neighbour matter? Journal of Banking and Finance, 36(4), 1194-1209.

Lawrence, T.B., and Robinson, S.L. (2005) Territoriality in organizations. Academy of Management Review, 30, 577-594.

Leary, M. and Roberts R. (2014) Do Peer Firms Affect Corporate Financial Policy? The Journal of Finance, 69(1), 139-178.

Lee, C.F., and Wu, C. (1988) Expectation formation and financial ratio adjustment processes, Accounting Review, 292-306.

Lee, L.F., and Yu, J. (2010b) Some recent developments in spatial panel data models. Regional Science and Urban Economics 40:255-271

Lee, L.F., and Yu, J. (2012) Spatial panels: Random components versus fixed effects. International Economic Review, 53:1369-1388

Lee, L.F., Yu, J. (2010a) Estimation of spatial autoregressive panel data models with fixed effects. Journal of Econometrics 154:165-185

LeSage J.P, and Pace R.K. (2009) Introduction to spatial econometrics. CRC Press Taylor \& Francis Group, Boca Raton

Lev, B., (1969) Industry Averages as Targets for Financial Ratios, Journal of Accounting Research, 290-299.

López F.A., Matilla M., Mur J. and Ruiz M. (2011) Four Tests of Independence in spatio-temporal data, Papers Regional Science. 90 (3) 663-685

Low, P., Chen, K., (2004) Diversification and capital structure: some international evidence. Rev. Quant. Finance Account. 23, 55-71.

Manski, C. (1993) Identification of Endogenous Social Effects: The Reflection Poblem. The Review of Economic Studies, 60 531-542.

Massa, M., and Simonov, A. (2006) Hedging, familiarity and portfolio choice. Review of Financial Studies, 19(2), 633-685.

Mate, M.L, López F.A. and Mur J. (2012) Analysing Long Term Average Adjustment of Financial Ratios with Spatial Interactions, Economic Modelling, 29, 1370-1376.

Michelacci, C., and Silva, O. (2007) Why so many local entrepreneurs? Review of Economics and Statistics, 89: 615-633.

Mizruchi, M. (1996) What do interlocks do? An analysis, critique, and assessment of research on interlocking directorates, Annual Review of Sociology, 22, 271-298.

Moran, P.A. (1948) The interpretation of statistical maps, Journal of the Royal Statistical Society, Series B (10): 243-51. 
O’Brien, P. and Tan, H. (2015) Geographic proximity and analyst coverage decisions: Evidence from IPOs. Journal of Accounting and Economy, 41-59.

Pacheco, L. (2016): Capital structure and internationalization: The case of Portuguese industrial SMEs Research in International Business and Finance 38 (2016) 531-545

Palacín-Sanchez, M.J. and Di Pietro, F. (2016) The Role of the Regional Financial Sector in the Capital Structure of Small and Medium-Sized Enterprises (SMEs) Regional Studies, 50(7), 1232-1247.

Palacín-Sanchez, M.J., Ramirez-Herrera, L.M. and Di Pietro,. (2013) Capital structure of SMEs in Spanish regions. Small Business Economics, 41(2), 503-519.

Peles, Y. and Schneller, M., (1989) The duration of the adjustment process of financial ratios. The Review of Economics and Statistics, 62, 527-532.

Pirinsky, C., and Wang, Q. (2010) Geographic location and corporate finance: a review. In: Tourani-Rad, A., Ingley, C.C. (Eds.), Handbook of Emerging Issues in Corporate Governance. World Scientific Publishing, Singapore.

Rao, P., Yue, J. and Zhu, J. (2015) An investigation of credit borrower concentration Journal of Banking and Finance, 54, 208-221.

Reppenhagen, D. (2010) Contagion of accounting methods: evidence from stock option expensing. Review of Accounting Studies, 15(3), 629-657.

Seay, S.S., Pitts, S.T., and Kamery, R.H. (2004) The Contribution of Firm-specific Factors: Theory Development of the Ratio Adjustment Process. Academy of Strategic Management, 27.

Soboh, R.A., Lansink, A.O., Giesen, G. and Van-Dijk, G. (2009) Performance Measurement of the Agricultural Marketing Cooperatives: The Gap Between Theory and Practice. Applied Economic Perspectives and Policy, 31, 446-469.

Tomas, M. (2015): If Urban Regions are the Answer, What is the Question? Thoughts on the European Experience. International Journal of Urban and Regional Research. 39(2), 382-389.

Treacy, W. and Carey, M. (2000) Credit risk rating system at large US banks, Journal of Banking and Finance, 24, 167-201.

Uysal, V.B., Kedia, S., and Panchapagesan, V. (2008) Geography and acquirer returns. Journal of Financial Intermediation, 17(2), 256-275.

Wu, C., and Ho, S.K. (1997) Financial Ratio Adjustment: Industry-Wide Effects on Strategic Management, Review of Quantitative Finance and Accounting, 9, 71-88. 
Zwiebel, J. (1995) Corporate conservatism and relative compensation, Journal of Political Economy, 103, 1-25. 
Table 1: Factors influencing the adjustment process in the PAM equation

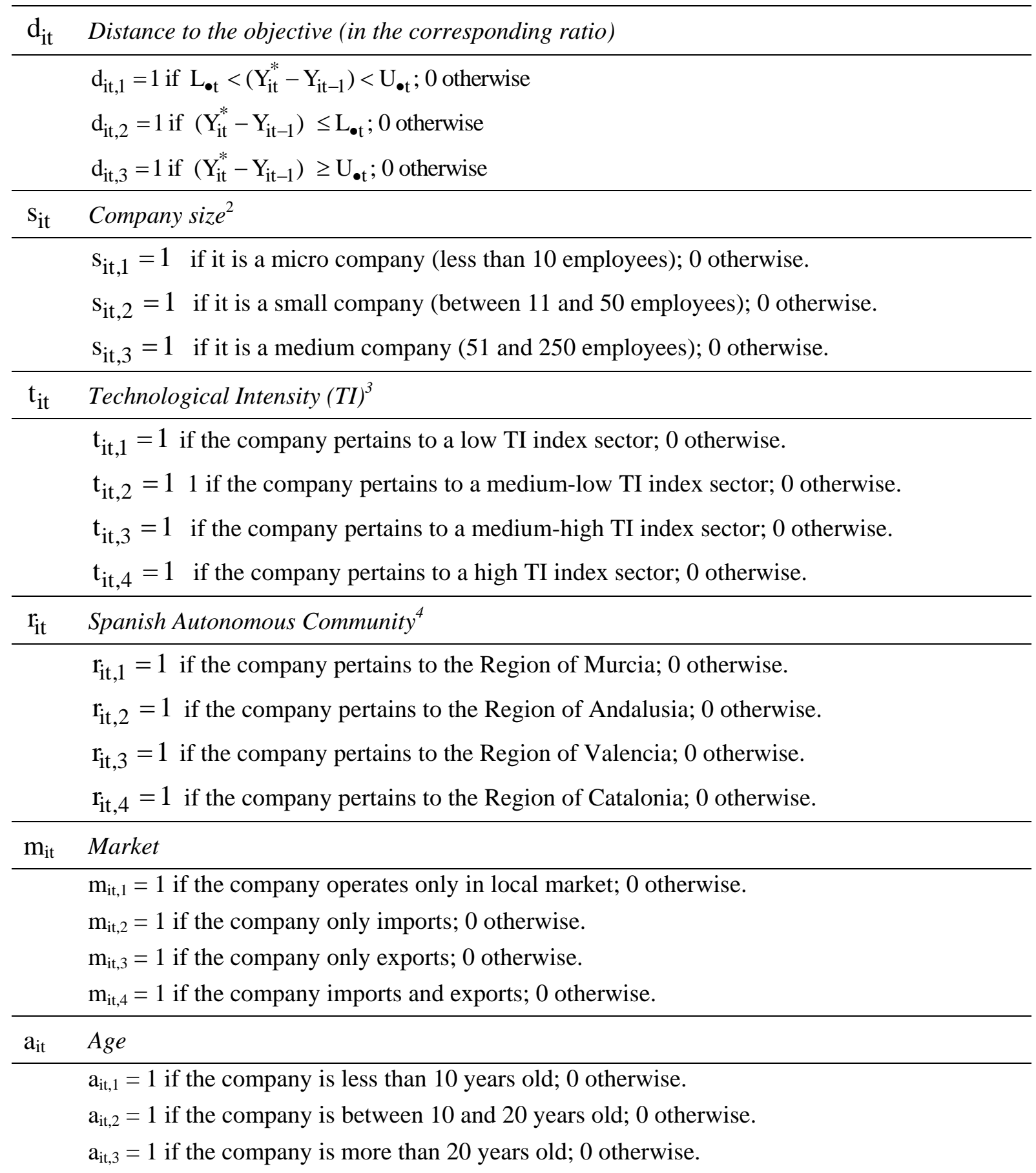

$\mathrm{L}_{\bullet t}$ and $\mathrm{U}_{\bullet t}$ indicate the percentiles of $10 \%$ and $90 \%$ respectively in the distribution of gaps to the optimum in the corresponding ratio, in period t.

\footnotetext{
2 European Commission (2003) considers a medium size company if the number of employees is between 51 and 250.

${ }^{3}$ According to the Statistical Classification of Economic Activities of the European Community.

${ }^{4}$ Autonomous Community corresponds to Eurostar NUTS II regions.
} 
Table 2: Descriptive analysis of companies in the sample by categories.

\begin{tabular}{|c|c|c|c|c|c|c|c|c|c|c|c|c|c|c|}
\hline & \multicolumn{2}{|c|}{ Companies } & \multicolumn{4}{|c|}{ CU } & \multicolumn{4}{|c|}{$\mathrm{DE}$} & \multicolumn{4}{|c|}{ PR } \\
\hline & $\mathrm{N}$ & $\%$ & Min & Max & Mean & SD & Min & Max & Mean & SD & Min & Max & Mean & SD \\
\hline & \multicolumn{14}{|c|}{ by the Gap ${ }^{\ddagger}$} \\
\hline $\mathrm{Y}^{*}{ }_{\mathrm{it}}-\mathrm{Y}_{\mathrm{it}-1}<\mathrm{P}_{10}$ & 1244 & $10 \%$ & 0.08 & 2.64 & 0.76 & 0.29 & 0.01 & 0.68 & 0.32 & 0.08 & 0.05 & 1.95 & 0.55 & 0.23 \\
\hline $\mathrm{P}_{10}<\mathrm{Y}^{*}{ }_{\mathrm{it}}-\mathrm{Y}_{\mathrm{it}-1}<\mathrm{P}_{90}$ & 9955 & $80 \%$ & 0.53 & 3.92 & 1.58 & 0.51 & 0.21 & 0.95 & 0.63 & 0.15 & 0.37 & 3.52 & 1.42 & 0.47 \\
\hline \multirow[t]{2}{*}{$\mathrm{Y}_{\mathrm{it}}^{*} \mathrm{Y}_{\mathrm{it}-1}>\mathrm{P}_{90}$} & 1244 & $10 \%$ & 1.33 & 4.36 & 2.83 & 0.53 & 0.56 & 0.99 & 0.89 & 0.06 & 1.02 & 4.67 & 2.70 & 0.53 \\
\hline & \multicolumn{14}{|c|}{ by Size $^{\dagger}$} \\
\hline Micro & 6991 & $56.2 \%$ & 0.10 & 4.36 & 1.59 & 0.68 & 0.01 & 0.99 & 0.65 & 0.19 & 0.05 & 4.38 & 1.43 & 0.69 \\
\hline Small & 4569 & $36.7 \%$ & 0.08 & 4.25 & 1.66 & 0.68 & 0.11 & 0.99 & 0.60 & 0.18 & 0.06 & 4.39 & 1.50 & 0.64 \\
\hline \multirow[t]{2}{*}{ Medium } & 884 & $7.1 \%$ & 0.13 & 4.01 & 1.65 & 0.68 & 0.14 & 0.99 & 0.56 & 0.17 & 0.27 & 4.67 & 1.47 & 0.61 \\
\hline & \multicolumn{14}{|c|}{ by Technological Intensity $^{\dagger}$} \\
\hline Low TI & 5676 & $45.6 \%$ & 0.08 & 4.25 & 1.56 & 0.68 & 0.11 & 0.99 & 0.63 & 0.19 & 0.05 & 4.67 & 1.47 & 0.72 \\
\hline Medium-Low TI & 4480 & $36.0 \%$ & 0.20 & 4.18 & 1.64 & 0.68 & 0.01 & 0.99 & 0.62 & 0.18 & 0.05 & 4.19 & 1.42 & 0.62 \\
\hline Medium High TI & 2058 & $16.5 \%$ & 0.10 & 4.36 & 1.73 & 0.67 & 0.16 & 0.99 & 0.60 & 0.18 & 0.13 & 4.39 & 1.49 & 0.61 \\
\hline \multirow[t]{2}{*}{ High TI } & 230 & $1.9 \%$ & 0.27 & 4.09 & 1.79 & 0.74 & 0.18 & 0.98 & 0.58 & 0.19 & 0.09 & 3.42 & 1.42 & 0.62 \\
\hline & \multicolumn{14}{|c|}{ by Region $^{\dagger}$} \\
\hline Andalusia & 987 & $7.9 \%$ & 0.14 & 3.76 & 1.33 & 0.63 & 0.14 & 0.99 & 0.67 & 0.18 & 0.05 & 4.21 & 1.23 & 0.71 \\
\hline Murcia & 840 & $6.7 \%$ & 0.18 & 3.97 & 1.45 & 0.60 & 0.12 & 0.99 & 0.65 & 0.18 & 0.08 & 3.50 & 1.25 & 0.58 \\
\hline Catalonia & 6404 & $51.5 \%$ & 0.10 & 4.36 & 1.71 & 0.69 & 0.11 & 0.99 & 0.60 & 0.18 & 0.08 & 4.67 & 1.55 & 0.67 \\
\hline \multirow[t]{2}{*}{ Valencia } & 4213 & $33.9 \%$ & 0.08 & 4.19 & 1.59 & 0.66 & 0.01 & 0.99 & 0.64 & 0.19 & 0.05 & 4.39 & 1.41 & 0.64 \\
\hline & \multicolumn{14}{|c|}{ by Market $^{\dagger}$} \\
\hline Local market & 7759 & $62.3 \%$ & 0.08 & 4.36 & 1.57 & 0.68 & 0.10 & 0.99 & 0.64 & 0.19 & 0.05 & 4.39 & 1.45 & 0.70 \\
\hline Only Import & 932 & $7.5 \%$ & 0.25 & 4.25 & 1.64 & 0.66 & 0.11 & 0.98 & 0.62 & 0.18 & 0.10 & 3.84 & 1.50 & 0.63 \\
\hline Only Export & 1177 & $9.5 \%$ & 0.31 & 4.19 & 1.69 & 0.67 & 0.14 & 0.99 & 0.60 & 0.18 & 0.10 & 4.67 & 1.43 & 0.67 \\
\hline \multirow[t]{2}{*}{ Import/Export } & 2576 & 20.7 & 0.13 & 4.25 & 1.72 & 0.67 & 0.01 & 0.99 & 0.59 & 0.18 & 0.06 & 4.35 & 1.47 & 0.58 \\
\hline & \multicolumn{14}{|c|}{ by Age $^{\dagger}$} \\
\hline$<10$ & 853 & $6.9 \%$ & 0.21 & 3.44 & 1.48 & 0.60 & 0.20 & 0.99 & 0.71 & 0.17 & 0.11 & 3.82 & 1.68 & 0.73 \\
\hline $10 \leq$ Age $\leq 20$ & 5954 & $47.8 \%$ & 0.12 & 4.10 & 1.51 & 0.64 & 0.12 & 0.99 & 0.66 & 0.18 & 0.05 & 4.67 & 1.47 & 0.69 \\
\hline$>20$ & 5637 & $45.3 \%$ & 0.08 & 4.36 & 1.75 & 0.71 & 0.01 & 0.99 & 0.56 & 0.18 & 0.08 & 4.33 & 1.41 & 0.62 \\
\hline TOTAL & 12444 & $100 \%$ & 0.08 & 4.36 & 1.62 & 0.68 & 0.01 & 0.99 & 0.62 & 0.19 & 0.05 & 4.67 & 1.46 & 0.67 \\
\hline
\end{tabular}


Table 3: Moran I and STMI statistics of global spatial autocorrelation.

\begin{tabular}{|c|c|c|c|c|c|c|c|c|}
\hline \multirow{2}{*}{ Variable } & \multirow{2}{*}{$\mathbf{W}$} & \multicolumn{6}{|c|}{ Moran I for periods t-(t-1) } & \multirow{2}{*}{ STMI } \\
\hline & & 11-12 & 10-11 & 09-10 & 08-09 & 07-08 & 06-07 & \\
\hline \multirow{4}{*}{$\mathrm{CU}_{\mathrm{it}}-\mathrm{CU}_{\mathrm{it}-1}$} & $\mathrm{~W}_{5 \mathrm{~km}}$ & $1.84^{*}$ & 1.29 & 0.59 & 0.16 & -0.84 & 0.00 & $4.02^{* * *}$ \\
\hline & $\mathrm{W}_{10 \mathrm{~km}}$ & $1.69^{*}$ & -0.05 & -0.38 & -0.22 & $1.82^{*}$ & -0.18 & $5.31^{* * *}$ \\
\hline & $\mathrm{W}_{25 \mathrm{nn}}$ & $1.44^{*}$ & 1.11 & 0.13 & -0.84 & -1.16 & 0.15 & $3.39^{* * *}$ \\
\hline & $\mathrm{W}_{50 \mathrm{nn}}$ & $2.11^{* *}$ & $1.85^{* *}$ & 0.55 & -0.19 & 0.33 & -0.48 & $6.34^{* * *}$ \\
\hline \multirow{4}{*}{$\mathrm{DE}_{\mathrm{it}}-\mathrm{DE}_{\mathrm{it}-1}$} & $\mathrm{~W}_{5 \mathrm{~km}}$ & 0.15 & 0.57 & -1.56 & 1.10 & 0.51 & 0.04 & $6.87^{* * *}$ \\
\hline & $\mathrm{W}_{10 \mathrm{~km}}$ & 0.78 & 0.48 & 0.00 & 0.55 & 1.58 & 0.84 & $11.49^{* * *}$ \\
\hline & $\mathrm{W}_{25 \mathrm{nn}}$ & -0.31 & $1.64^{*}$ & 0.97 & $1.82^{* *}$ & -1.27 & -0.05 & $8.79^{* * *}$ \\
\hline & $\mathrm{W}_{50 \mathrm{nn}}$ & 0.60 & $2.21^{* *}$ & $2.39^{* *}$ & $2.26^{* *}$ & 0.09 & 0.78 & $14.38^{* * *}$ \\
\hline \multirow{4}{*}{$\mathrm{PR}_{\mathrm{it}}-\mathrm{PR}_{\mathrm{it}-1}$} & $\mathrm{~W}_{5 \mathrm{~km}}$ & 0.51 & $3.46^{* * *}$ & $4.30^{* * *}$ & $6.89^{* * *}$ & $3.04^{* * *}$ & $2.11^{* *}$ & $63.34^{* * *}$ \\
\hline & $\mathrm{W}_{10 \mathrm{~km}}$ & 1.39 & $4.27^{* * *}$ & $5.29^{* * *}$ & $7.59^{* * *}$ & $3.59^{* * *}$ & $3.59^{* * *}$ & $92.84^{* * *}$ \\
\hline & $\mathrm{W}_{25 \mathrm{nn}}$ & $1.45^{*}$ & $4.66^{* * *}$ & $5.75^{* * *}$ & $9.41^{* * *}$ & $2.68^{* * *}$ & $3.13^{* * *}$ & $75.60^{* * *}$ \\
\hline & $\mathrm{W}_{50 \mathrm{nn}}$ & $1.72^{*}$ & $4.32^{* * *}$ & $6.40^{* * *}$ & $11.41^{* * *}$ & $4.46^{* * *}$ & $4.22^{* * *}$ & $105.81^{* * *}$ \\
\hline
\end{tabular}


Table 4: Estimate of the baseline PAM model, SLX version (contiguity matrix: $\mathbf{W}_{50 \mathrm{mn}}$ )

\begin{tabular}{|c|c|c|c|c|c|c|}
\hline & CU & $\mathrm{F}_{\mathrm{k}}$ & $\mathrm{DE}$ & $\mathrm{F}_{\mathrm{k}}$ & PR & $\mathrm{F}_{\mathrm{k}}$ \\
\hline$\delta$ & $0.515^{* * *}$ & & $0.440^{* * *}$ & & $0.600^{* * *}$ & \\
\hline$\delta^{\mathrm{L}}$ spatial lag & -0.038 & & $-0.082^{* * *}$ & & $-0.116^{* * *}$ & \\
\hline$\delta_{\mathrm{d} 2}$ (below 10\% gap) & $0.156^{* * *}$ & \multirow{2}{*}{$320.40^{* * *}$} & 0.007 & \multirow{2}{*}{$25.64^{* * *}$} & $0.092^{* * *}$ & \multirow{2}{*}{$199.21^{* * *}$} \\
\hline$\delta_{\mathrm{d} 3}$ (above $90 \%$ gap) & -0.012 & & $0.039^{* * *}$ & & $-0.018^{* * *}$ & \\
\hline$\delta_{\mathrm{s} 2}($ small size $)$ & $-0.034^{* * *}$ & \multirow{2}{*}{0.00} & $-0.017^{* * *}$ & \multirow{2}{*}{0.05} & $-0.026^{* * *}$ & \multirow{2}{*}{$38.93^{* * *}$} \\
\hline$\delta_{\mathrm{s} 3}(\mathrm{med} /$ large size $)$ & $-0.034^{* *}$ & & $-0.028^{* *}$ & & $-0.108^{* *}$ & \\
\hline$\delta_{\mathrm{t} 2}($ low/med tech) & 0.004 & \multirow{3}{*}{4.51} & $0.015^{* *}$ & & $0.016^{* * *}$ & \multirow{3}{*}{$30.92^{* * *}$} \\
\hline$\delta_{\mathrm{t} 3}(\mathrm{med} / \mathrm{high}$ tech $)$ & $0.022^{* *}$ & & $0.028^{* * *}$ & 2.78 & 0.071 & \\
\hline$\delta_{\mathrm{t} 4}($ high tech) & -0.020 & & $0.041^{*}$ & & $-0.001^{* * *}$ & \\
\hline$\delta_{\mathrm{r} 2}$ (Andalusia) & $0.067^{* * *}$ & \multirow{3}{*}{0.35} & $0.029^{*}$ & \multirow{3}{*}{$11.99^{* * *}$} & $0.052^{* * *}$ & \multirow{3}{*}{0.31} \\
\hline$\delta_{\mathrm{r} 3}($ Valencia $)$ & $0.059^{* * *}$ & & $0.072^{* * *}$ & & $0.047^{* * *}$ & \\
\hline$\delta_{\mathrm{r} 4}$ (Catalonia) & $0.063^{* * *}$ & & $0.067^{* * *}$ & & $0.050^{* * *}$ & \\
\hline$\delta_{\mathrm{m} 2}$ (Import) & 0.023 & \multirow{3}{*}{1.05} & $0.048^{* * *}$ & & $0.068^{* * *}$ & \multirow{3}{*}{1.21} \\
\hline$\delta_{\mathrm{m} 3}$ (Export) & $0.040^{* * *}$ & & $0.034^{* * *}$ & 4.54 & $0.075^{* * *}$ & \\
\hline$\delta_{\mathrm{m} 4}$ (Import/Export) & $0.027^{* *}$ & & $0.063^{* * *}$ & & $0.084^{* * *}$ & \\
\hline$\delta_{\mathrm{a} 2}(10<$ old $<20$ years $)$ & $-0.034^{* *}$ & \multirow{2}{*}{$32.31^{* * *}$} & $-0.029^{* *}$ & \multirow{2}{*}{$25.52^{* * *}$} & $-0.068^{* * *}$ & \multirow{2}{*}{3.21} \\
\hline$\delta_{\mathrm{a} 3}($ old $>20$ years $)$ & $-0.078^{* * *}$ & & $-0.064^{* * *}$ & & $-0.081^{* * *}$ & \\
\hline$\sigma^{2}$ & 0.170 & & 0.005 & & 0.106 & \\
\hline $\mathrm{R}^{2}$ & 0.304 & & 0.240 & & 0.352 & \\
\hline LogLik & -39896.8 & & 93396.2 & & -22278.0 & \\
\hline \multicolumn{7}{|l|}{ Diagnostic Tests } \\
\hline LR tests for time+indiv. effects & $1608.7^{* * *}$ & & $3114.2^{* * *}$ & & $2255.2 * * *$ & \\
\hline Hausman test & $1045.7^{* * *}$ & & $1264.5^{* * *}$ & & $1014.5^{* * *}$ & \\
\hline STMI & $3.02^{* * *}$ & & $4.38^{* *}$ & & $13.91^{* * *}$ & \\
\hline LM spatial lag & $9.57^{* * *}$ & & $20.09^{* * *}$ & & $192.90^{* * *}$ & \\
\hline LM spatial error & $8.98^{* * *}$ & & $19.06^{* * *}$ & & $192.93^{* *}$ & \\
\hline
\end{tabular}

p-value $<0.01 ;{ }^{* *}$-value $<0.05 ;{ }^{*}$-value $<0.1$

$\mathrm{F}_{\mathrm{k}}$ : $\mathrm{F}$ tests for the significance of the respective group of multiplicative dummy variables. 
Table 5: Estimates of the Spatial Durbin panel data model ${ }^{\dagger}$ (contiguity matrix: $\mathbf{W}_{50 \mathrm{nn}}$ )

\begin{tabular}{|c|c|c|c|c|c|c|}
\hline & CU & $\chi_{\mathrm{k}}^{2}$ & $\mathrm{DE}$ & $\chi_{k}^{2}$ & PR & $\chi_{\mathrm{k}}^{2}$ \\
\hline$\delta$ & $0.555^{* * *}$ & & $0.445^{* * *}$ & & $0.616^{* * *}$ & \\
\hline$\delta^{\mathrm{L}-\text { spatial lag }}$ & $-0.090^{* * *}$ & & $-0.114^{* *}$ & & $-0.235^{* * *}$ & \\
\hline$\delta_{\mathrm{d} 2}$ (below $10 \%$ gap) & $0.123^{* * *}$ & \multirow{2}{*}{$161.5^{* * *}$} & $0.010^{* *}$ & \multirow{2}{*}{$23.50^{* * *}$} & $0.068^{* * *}$ & \multirow{2}{*}{$88.24^{* * *}$} \\
\hline$\delta_{\mathrm{d} 3}$ (above $90 \%$ gap) & $0.023^{* * *}$ & & $0.036^{* * *}$ & & 0.008 & \\
\hline$\delta_{\mathrm{s} 2}($ small size $)$ & $-0.033^{* * *}$ & \multirow{2}{*}{0.00} & $-0.018^{* * *}$ & \multirow{2}{*}{1.06} & $-0.029^{* * *}$ & \multirow{2}{*}{$88.03^{* * *}$} \\
\hline$\delta_{\mathrm{s} 3}(\mathrm{med} / \mathrm{large}$ size $)$ & $-0.028^{*}$ & & $-0.029^{* *}$ & & $-0.110^{* * *}$ & \\
\hline$\delta_{\mathrm{t} 2}($ low/med tech) & -0.001 & \multirow{3}{*}{3.80} & $0.014^{* *}$ & \multirow{3}{*}{2.80} & $0.018^{* *}$ & \multirow{3}{*}{$28.77^{* * *}$} \\
\hline$\delta_{\mathrm{t} 3}(\mathrm{med} / \mathrm{high}$ tech) & 0.013 & & $0.027^{* * *}$ & & $0.071^{* * *}$ & \\
\hline$\delta_{\mathrm{t} 4}($ high tech) & -0.030 & & $0.040^{*}$ & & 0.004 & \\
\hline$\delta_{\mathrm{r} 2}$ (Andalusia) & $0.073^{* * *}$ & \multirow{3}{*}{3.58} & $0.030^{*}$ & \multirow{3}{*}{$11.42^{* * *}$} & $0.052^{* * *}$ & \multirow{3}{*}{2.96} \\
\hline$\delta_{\mathrm{r} 3}($ Valencia $)$ & $0.049^{* * *}$ & & $0.071^{* * *}$ & & $0.036^{* *}$ & \\
\hline$\delta_{\mathrm{r} 4}$ (Catalonia) & $0.046^{* * *}$ & & $0.064^{* * *}$ & & $0.031^{* *}$ & \\
\hline$\delta_{\mathrm{m} 2}$ (Import) & 0.023 & \multirow{3}{*}{0.77} & $0.048^{* * *}$ & \multirow{3}{*}{4.22} & $0.066^{* * *}$ & \multirow{3}{*}{1.53} \\
\hline$\delta_{\mathrm{m} 3}($ Export $)$ & $0.035^{* * *}$ & & $0.033^{* * *}$ & & $0.079^{* * *}$ & \\
\hline$\delta_{\mathrm{m} 4}$ (Import/Export) & $0.023^{* *}$ & & $0.062^{* * *}$ & & $0.085^{* * *}$ & \\
\hline$\delta_{\mathrm{a} 2}(10<$ old $<20$ years $)$ & $-0.034^{* *}$ & \multirow{2}{*}{$55.88^{* * *}$} & $-0.030^{* *}$ & \multirow{2}{*}{$34.41^{* * *}$} & $-0.061^{* * *}$ & \multirow{2}{*}{1.04} \\
\hline$\delta_{\mathrm{a} 3}($ old $>20$ years $)$ & $-0.091^{* * *}$ & & $-0.068^{* * *}$ & & $-0.069^{* * *}$ & \\
\hline$\rho$ & $0.055^{* *}$ & & $0.072^{* *}$ & & $0.185^{* * *}$ & \\
\hline$\sigma^{2}$ & 0.171 & & 0.005 & & 0.106 & \\
\hline $\mathrm{R}^{2}$ & 0.366 & & 0.351 & & 0.450 & \\
\hline Log-Lik & -39883.6 & & 93402.3 & & -22272.4 & \\
\hline \multicolumn{7}{|l|}{ Diagnostic Tests } \\
\hline STMI & -0.05 & & 0.23 & & 1.08 & \\
\hline LR test & $26.4^{* * *}$ & & $13.2^{* * *}$ & & $11.93^{* * *}$ & \\
\hline
\end{tabular}

${ }^{* * * *}$ p-value $<0.01 ;{ }^{* * *}$-value $<0.05 ;{ }^{*}$ p-value $<0.1$

${ }^{\dagger}$ The bias-correction of Lee and Yu (2010) was used in the estimation.

$\chi_{\mathrm{k}}^{2}$ : Chi-squared test for the significance of the respective group of multiplicative dummy variables. 
Table 6: Estimated Direct, Indirect and Total effects for the Spatial Durbin Model Direct effects Indirect effects

\begin{tabular}{|c|c|c|c|c|c|c|c|c|c|}
\hline & & & & & & & \\
\hline & $\mathrm{CU}$ & $\mathrm{DE}$ & PR & $\mathrm{CU}$ & $\mathrm{DE}$ & PR & $\mathrm{CU}$ & $\mathrm{DE}$ & PR \\
\hline$\delta$ & $0.576^{* * *}$ & $0.459^{* * *}$ & $0.627^{* * *}$ & $-0.061^{* * *}$ & $-0.086^{* * *}$ & $-0.147^{* * *}$ & $0.515^{* * *}$ & $0.373^{* * *}$ & $0.480^{* * *}$ \\
\hline$\delta_{\mathrm{d} 2}$ (below 10\% gap) & $0.120^{* * *}$ & $0.009^{*}$ & $0.068^{* * *}$ & $0.008^{* * *}$ & $0.001^{*}$ & $0.018^{* * *}$ & $0.129^{* * *}$ & $0.010^{*}$ & $0.086^{* * *}$ \\
\hline$\delta_{\mathrm{d} 3}$ (above $90 \%$ gap) & $0.032^{* * *}$ & $0.037^{* * *}$ & 0.008 & $0.002^{* * *}$ & $0.003^{* * *}$ & 0.002 & $0.034^{* * *}$ & $0.040^{* * *}$ & 0.010 \\
\hline$\delta_{\mathrm{s} 2}($ small size $)$ & $-0.035^{* * *}$ & $-0.018^{* * *}$ & $-0.029^{* * *}$ & $-0.002^{* * *}$ & $-0.002^{* * *}$ & $-0.008^{* * *}$ & $-0.037^{* * *}$ & $-0.019^{* * *}$ & $-0.037^{* * *}$ \\
\hline$\delta_{\mathrm{s} 3}(\mathrm{med} /$ large size $)$ & 0.006 & $-0.028^{* *}$ & $-0.109^{* * *}$ & 0.000 & $-0.003^{* *}$ & $-0.028^{* * *}$ & 0.006 & $-0.030^{* *}$ & $-0.137^{* * *}$ \\
\hline$\delta_{\mathrm{t} 2}($ low/med tech) & -0.001 & $0.016^{* *}$ & $0.020^{* * *}$ & 0.000 & $0.001^{* *}$ & $0.005^{* * *}$ & -0.001 & $0.017^{* *}$ & $0.025^{* * *}$ \\
\hline$\delta_{\mathrm{t} 3}(\mathrm{med} / \mathrm{high}$ tech $)$ & 0.010 & $0.029^{* * *}$ & $0.073^{* * *}$ & 0.001 & $0.003^{* * *}$ & $0.019^{* * *}$ & 0.010 & $0.032^{* * *}$ & $0.092^{* * *}$ \\
\hline$\delta_{\mathrm{t} 4}($ high tech) & -0.028 & $0.041^{*}$ & 0.006 & -0.002 & $0.004^{*}$ & 0.002 & -0.030 & $0.045^{*}$ & 0.008 \\
\hline$\delta_{\mathrm{r} 2}$ (Andalusia) & $0.039^{* * * *}$ & 0.013 & $0.040^{* *}$ & $0.003^{* * *}$ & 0.001 & $0.011^{* *}$ & $0.041^{* * *}$ & 0.014 & $0.051^{* *}$ \\
\hline$\delta_{\mathrm{r} 3}($ Valencia $)$ & $0.030^{*}$ & $0.062^{* * * *}$ & $0.025^{*}$ & $0.002^{*}$ & $0.006^{* * * *}$ & $0.006^{*}$ & $0.032^{*}$ & $0.067^{* * * *}$ & $0.031^{*}$ \\
\hline$\delta_{\mathrm{r} 4}$ (Catalonia) & $0.027^{*}$ & $0.049^{* * * *}$ & 0.019 & $0.002^{*}$ & $0.004^{* * *}$ & 0.005 & $0.029^{*}$ & $0.053^{* * *}$ & 0.024 \\
\hline$\delta_{\mathrm{m} 2}$ (Import) & 0.008 & $0.048^{* * *}$ & $0.068^{* * *}$ & 0.001 & $0.004^{* * *}$ & $0.018^{* * * *}$ & 0.008 & $0.052^{* * *}$ & $0.085^{* * *}$ \\
\hline$\delta_{\mathrm{m} 3}$ (Export) & $0.040^{* * * *}$ & $0.033^{* *}$ & $0.080^{* * *}$ & $0.003^{* * *}$ & $0.003^{* *}$ & $0.021^{* * *}$ & $0.042^{* * *}$ & $0.036^{* *}$ & $0.101^{* * *}$ \\
\hline$\delta_{\mathrm{m} 4}$ (Import/Export) & $0.003^{*}$ & $0.060^{* * *}$ & $0.086^{* * *}$ & $0.000^{*}$ & $0.005^{* * *}$ & $0.022^{* * *}$ & $0.003^{*}$ & $0.066^{* * *}$ & $0.108^{* * *}$ \\
\hline$\delta_{\mathrm{a} 2}(10<$ old $<20$ years $)$ & $-0.048^{* *}$ & $-0.028^{* *}$ & $-0.060^{* * *}$ & $-0.003^{* *}$ & $-0.003^{* *}$ & $-0.016^{* * *}$ & $-0.051^{* *}$ & $-0.031^{* *}$ & $-0.076^{* * *}$ \\
\hline$\delta_{\mathrm{a} 3}($ old $>20$ years $)$ & $-0.099^{* * *}$ & $-0.066^{* * *}$ & $-0.068^{* * *}$ & $-0.007^{* * *}$ & $-0.006^{* * *}$ & $-0.018^{* * *}$ & $-0.105^{* * *}$ & $-0.072^{* * *}$ & $-0.085^{* * *}$ \\
\hline
\end{tabular}


Figure 1: Location of companies in the sample

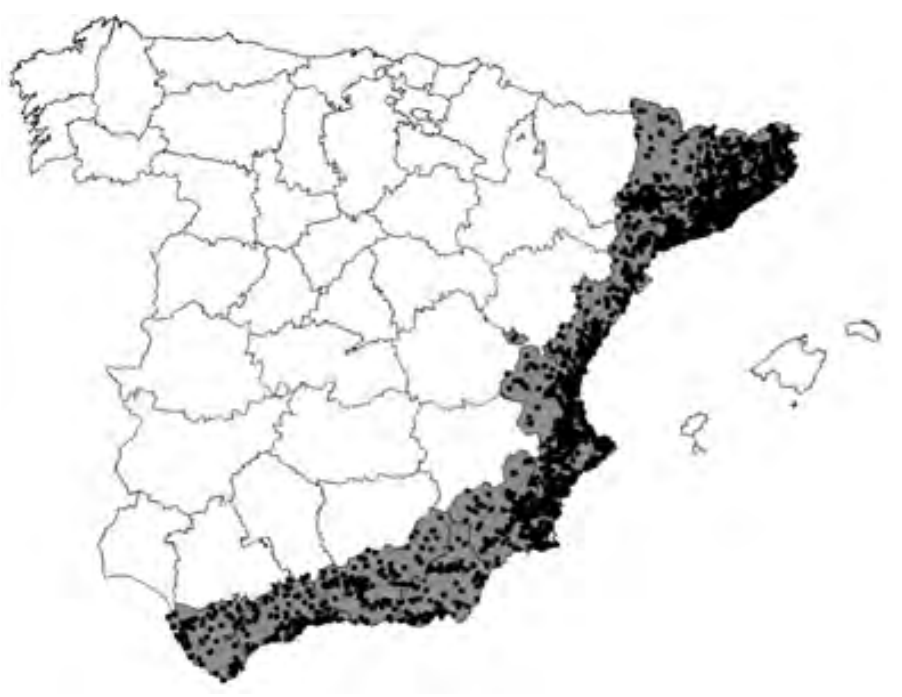


Figure 2: Local $G_{i}$ Getis-Ord cluster maps (2012)

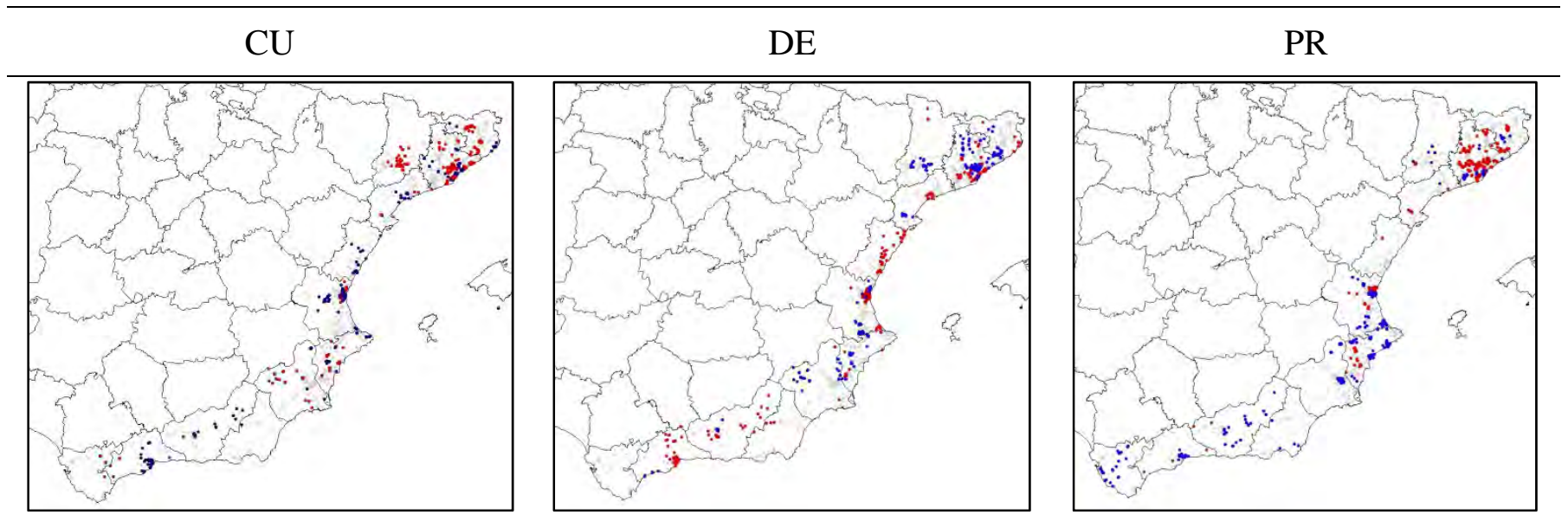

Spanish Nuts III units (provinces). In red, companies with High-High $\mathrm{G}_{\mathrm{i}}$ values for the ratio. In blue, companies with LowLow $G_{i}$ values for the ratio. In grey, companies with non-significant $G_{i}$ values for the ratio. 